\title{
CONTINGÊNCIA, DISCURSO E HISTÓRIA: CONSIDERAÇÕES SOBRE A LINGUAGEM EM FOUCAULT E RORTY
}

\author{
CONTINGENCY, DISCOURSE AND HISTORY: CONSIDERATIONS ABOUT LANGUAGE ON \\ FOUCAULT AND RORTY
}

Mauricio Junior Rodrigues da Silva*

\section{RESUMO}

Com a finalidade de suscitar um questionamento sobre a linguagem no pensamento de Michel Foucault, especialmente em suas abordagens discursivas produzidas a partir da década de 1960, o presente artigo busca recuperar parte das discussões sobre a contingência da linguagem presentes na primeira parte da obra Contingência, Ironia e Solidariedade (1994), de Richard Rorty. Para o filósofo americano, não é possível compreender a linguagem como um meio de representação do mundo, isto é, o mundo não possui uma natureza intrínseca ou uma verdade oculta que seja capaz de ser desvelada pela linguagem. É a própria linguagem, por meio de seus jogos, que produz as verdades que são pactuadas no cotidiano. De certo modo, essa recusa da linguagem como medium representativo do mundo coincide com as abordagens discursivas presentes no pensamento de Michel Foucault, talvez o grande eixo dissociativo entre esses autores esteja no questionamento sobre o papel da história dentro desse processo de constituição das verdades. É justamente esse ponto de divergência que o presente texto busca explorar. Em outros termos, questionar-se-á se as noções de discurso, presentes em Arqueologia do Saber (2009) e A ordem do discurso (2008), podem se relacionar a uma compreensão de linguagem dada em sua pura contingência, como propõe Rorty.

PALAVRAS-CHAVE: Foucault. Rorty. Linguagem. Contingência. História.

\section{ABSTRACT}

In order to raise a question about language on Michel Foucault's thought, especially in its discursive approaches produced from the 1960s, this article aims to recover part of the discussions about the contingency of language present in the first part of the work

\footnotetext{
* Doutor em Psicologia pela Faculdade de Filosofia, Ciências e Letras de Ribeirão Preto, USP; Doutor em Linguística pela Faculdade de Ciências e Letras de Araraquara, UNESP. E-mail: mauriciojrs@ bol.com.br.
} 
Contingency, Irony and Solidarity (1994), from Richard Rorty. For the american philosopher, we cannot understand the language as a means of the world representation, that is, the world does not have an intrinsic nature or a hidden truth that is able to be unveiled by language. It is the language, itself, through its games, which produces the truths that are agreed upon in everyday life. In a sense, the refusal of language as a representative medium of the world coincides with the discursive approaches of Michel Foucault's thought, perhaps the major difference between these authors can be found in the role of history in the constitution of the truths. It is precisely this point of difference that the text aims to analyze. In other words, we will ask whether the discursive notions, presented in Archaeology of knowledge (2009) and The discourse on language (2008), can relate to an understanding of language, given by its pure contingency, as proposed by Rorty.

KEYWORDS: Foucault. Rorty. Language. Contingency. History.

\section{INTRODUÇÃO}

Espontaneidade da linguagem e receptividade da luz, [...] em Foucault, a esponeidade do entendimento, Cogito, é substituída pela da linguagem (o existe linguagem), enquanto receptividade, enquanto a receptividade da intuição é substituída pela luz (nova forma de espaço-tempo). (MACHADO, 2010, p. 169).

O excerto de Roberto Machado (2010) sobre visibilidade, entendimento e apreensão do conhecimento denota a importância da linguagem no pensamento foucaultiano. Segundo o autor, a substituição do Cogito pela linguagem, constante num primeiro momento da obra de Foucault, traz duas consequências imediatas: a passagem das condições de uma experiência possível, comuns ao kantismo, para uma experiência real; e o deslocamento do sujeito universal, através do qual o sentido de uma realidade se forma, para uma formação histórica que torna possível as noções de realidade e de ser humano (MACHADO, 2010).

Nesses deslocamentos, a linguagem, e de modo mais específico, os enunciados, ocupariam papéis fundamentais, uma vez que é por meio deles que se materializam as condições de possibilidade de um dado período. Segundo o próprio Foucault (2009, p. 90):

[...] o enunciado aparece [a princípio] como um elemento último, indecomponível, suscetível de ser isolado em si mesmo e capaz de entrar em um jogo de relações com outros elementos semelhantes a ele; [...] como um grão que aparece na superfície de um tecido de que é o elemento constituinte; como o átomo do discurso.

Sapere aude - Belo Horizonte, v. 7 - n. 12, p. 171-181, Jan./Jun. 2016 - ISSN: 2177-6342 
É para tratar desse tecido linguístico que o pensador americano Richard Rorty escreve a primeira parte de sua obra Contingência, Ironia e Solidariedade (1994), mostrando como a linguagem é contingente, uma vez que a verdade não está dada, mas é constantemente pactuada.

Posto isso, cabe ao presente trabalho recuperar parte das discussões empreendidas pelo filósofo americano e relacioná-las ao pensamento de Michel Foucault. Dito de modo mais específico, questionaremos como as noções de enunciado e discurso, constantes na obra Arqueologia do Saber (2009), de Foucault, se relacionam a uma possível incongruidade linguística, isto é, uma linguagem determinada em sua própria contingência, dada por sua aleatoriedade, que segundo Rorty (2010), pode ser encontrada nas filosofias da linguagem de Ludwig Wittgenstein e Donald Davidson.

\section{Contingência, ironia e solidariedade}

A obra Contingência, Ironia e Solidariedade (1994) de Richard Rorty, pode ser compreendida como uma peça de diagnóstico dos dilemas aportados pela modernidade, dentre os quais o embate entre o público e o privado. Essa relação entre público e privado traria de um lado - em autores como Marx, Mill, Habermas e Rawls - a busca por uma sociedade mais justa e menos cruel nas práticas sociais e na formação das instituições; e de outro - em autores como Kierkegaard, Nietzsche, Proust, Heidegger - a persecução de uma vida humana autocriada e autônoma. Sobre um meio termo entre esses dois valores, Rorty explica que:

O mais perto que chegaremos de unir essas duas buscas será considerar que a meta de uma sociedade justa e livre é deixar que seus cidadãos sejam tão privatistas, 'irracionalistas`, e esteticistas quanto lhes aprouver [...] sem causar prejuízos a terceiros. [...] não há como juntar autocriação com a justiça no nível teórico. (RORTY, 1994, p. 17).

O excerto rortyano é patente em descrever a incompatibilidade entre uma teoria pública e privada. Nas palavras de Rorty $(1994$, p. 18) "não há como fazer com que os dois falem a mesma língua". Diante disso, a obra mostra "como ficam as coisas [quando se abandona] a exigência de uma teoria que unifique [esses dois pólos]”.

Posto isso, a solução rortyana passa por termos que dão nome à obra: contingência, para preconizar "uma guinada contra a teoria e a favor da narrativa" (RORTY, 1994, p. 21); 
ironia, para designar uma qualidade presente em pessoas que enfrentam a contingência de suas convicções e desejos mais centrais e abandonam a ideia de que esses valores remontariam "a algo fora do alcance do tempo e do acaso"; e solidariedade, pensado não como um fato a ser reconhecido, mas como um objetivo a ser alcançado, sobretudo, pela "capacidade imaginativa de ver pessoas estranhas como semelhantes sofredores" (RORTY, 1994, p. 21).

Diante dessa perspectiva, cumpre-nos centrar no primeiro dos motes rortyanos: a contingência. É ela que torna possível uma guinada narrativa, um deslocamento em "nossa desistência de abarcar todas as facetas de nossa vida numa única visão, de descrevê-las como um só vocabulário" (RORTY, 1994, p. 21). A princípio, atentar-se à contingência da linguagem implica compreender que a verdade não está posta, dada, mas é pactuada nos diversos vocabulários compossíveis.

\section{A contingência da linguagem descrita por Rorty}

Historicamente, a ideia de uma verdade dada, e não criada, pode ser pensada a partir do movimento iluminista do século XVIII. Segundo Rorty (1994, p. 26), grande parte dos filósofos da Ilustração considera que a "ciência é a atividade humana paradigmática e insistem em que a ciência natural descobre a verdade ao invés de criá-la".

Para o pensador americano, esses filósofos nada mais são que utopistas políticos. Não é possível pensar qualquer descrição de mundo como sendo idêntica ao mundo em si. Em outros termos, "só as descrições de mundo podem ser verdadeiras ou falsas. O mundo em si — sem o auxílio das atividades descritivas dos seres humanos — não podem sê-lo" (RORTY, 1994, p. 28).

Dito de outro modo, a partir da perspectiva rortyana, o mundo, por si só, não fala, somente os seres humanos são capazes de fazê-lo. E o fazem a partir dos jogos de linguagem que circulam pela sociedade. Pensar a partir de tal assertiva implica em dizer que "as linguagens são feitas e não descobertas, e que a verdade é uma propriedade de entidades linguísticas, de frases" (RORTY, 1994, p. 31).

Rechaçar a possibilidade de um mundo que autonomamente fala implica a rejeição de uma linguagem enquanto medium, seja de representação, seja de expressão. Adotar essa perspectiva é essencial para o projeto rortyano, uma vez implica uma desdivinização do mundo. Segundo o próprio autor: 
Abandonar a ideia das línguas como representações [...] equivaleria a desdivinizar o mundo. Somente se o fizermos poderemos aceitar em sua plenitude a tese [...] de que a verdade é uma propriedade das frases, já que a existência das frases depende de vocabulários e já que os vocabulários são feitos por seres humanos, o mesmo se dá com as verdades. (RORTY, 1994, p. 54).

Dizer que a verdade é uma propriedade de frases não implica dizer que não existe verdade alguma. O que é mais adequado à perspectiva rortyana seria dizer que a verdade não é uma questão profunda a ser examinada. Nesse sentido, os problemas filosóficos remontariam antes a embates de vocabulários do que propriamente pela descoberta da essência de algo. Segundo as palavras de Rorty (1994, p. 34):

\begin{abstract}
A filosofia [...] em geral, de maneira implícita ou explícita, é uma disputa entre um vocabulário arraigado, que se transformou num incômodo, e um novo vocabulário, parcialmente formado, que traz a vaga promessa de coisas grandiosas.

[Este método] consiste em descrever uma porção de coisas de maneiras novas, até criar um padrão de conduta lingüística que tente a geração em ascensão a adotá-la, com isso fazendo-a buscar novas formas apropriadas de comportamento não linguístico.
\end{abstract}

Pensar nessa disputa de vocabulários, nesse jogo linguístico significa suscitar o pensamento do filósofo alemão Ludwig Wittgenstein, sobretudo presente em sua a obra Investigações Filosóficas (1953), uma vez que os jogos descritos por Rorty operam de forma circunstancial, com certos parâmetros e mecanismos de conservação. Essa aproximação é descrita José Carlos Mohallem da seguinte forma:

\begin{abstract}
Fundamentando-se no segundo Wittgenstein - que abandonou a busca por uma essência da linguagem -, Rorty vai arguir que abordamos o mundo dentro de um vocabulário, de jogos de linguagem, e nenhum deles está mais perto da descrição de como o mundo é em si mesmo. A noção de jogo de linguagem é a antítese da essência da linguagem. O que há de comum entre os diversos jogos? Absolutamente nada. Não há semelhança entre eles senão o fato de serem pautados por regras específicas de cada jogo. O uso significado é o uso que tem uma palavra, dentro de um jogo de linguagem específico. (MOHALLEM, 2008, p. 50).
\end{abstract}

Ao tratar da influência wittgensteiniana no pensamento de Rorty, Mohallem (2008) mostra como os significados se dão pelo simples uso, por uma necessidade humana, não obedecendo a critérios preestabelecidos que determinariam como o mundo deveria ser tratado. Segundo Rorty (1994, p. 48) essa perspectiva remontaria ao filósofo americano Donald Davidson, uma vez que "ter um significado [implica] ter um lugar num jogo de linguagem". 
Em suma, segundo essa perspectiva, as descrições de mundo remontariam aos usos de vocabulários em contextos distintos, do qual não haveria nenhuma consciência pré-lingüística ou senso profundo do qual a linguagem deveria obedecer. Em outros termos, para essa linha de pensamento a linguagem estaria exposta a sua mais "pura contingência" (RORTY, 1994, p. $55)$.

O problema que surge quando tratamos dessa temática sob uma perspectiva foucaultiana é: por que determinados usos se colocam e outros não? Malgrado tal problemática seja indiferente em Rorty e Wittgenstein, em Foucault ela é determinante. Contudo, só a abordaremos na quarta parte, ao tecermos um paralelo entre Foucault e Rorty. Antes é preciso mostrar como o pensador francês pensa a linguagem, o discurso e o enunciado.

\section{Apontamentos sobre a linguagem em Michel Foucault}

Como aduzido no excerto de Roberto Machado que enceta o presente trabalho, a linguagem tem grande importância no pensamento foucaultiano. É, sobretudo, nas obras Arqueologia do saber (2009) e A ordem do discurso (2008) que o pensador dedica maior parte de suas reflexões sobre o tema. Cabe-nos, portanto, recorrer a conceitos contidos nessas obras para suscitar essa temática.

Um dos conceitos presentes em Arqueologia do saber (2009) é o de enunciado. Na obra foucaultiana, ele não se reduz a um mero ato consciente de um sujeito intencional, tampouco a uma proposição lógica ou entidade psicológica (NARVAZ; NARDI; MORALES, 2006). Assim compreendidos, os enunciados se apresentam como condições de verdade, que fazem com que seja possível dizer algo de forma coerente e aceitável em uma dada conjuntura. De acordo com o próprio Foucaut (2009, p.98):

O enunciado não é, pois, uma estrutura [...]; é uma função de existência que pertence exclusivamente aos signos, e a partir da qual se pode decidir, em seguida, pela análise ou pela intuição, se eles fazem sentido ou não, segundo que regra se sucedem ou se justapõem, de qie são signos, e que espécie de ato se encontra realizado por sua formulação (oral ou escrita).

O trecho foucaultiano mostra como o enunciado é essa função que surge entre o que é visível e possível em uma dada época. Em outros termos, é “entre o visível e sua condição que 
os enunciados penetram [...]. É entre o enunciado e sua condição que as visibilidades se insinuam" (MACHADO, 2010, p. 168).

Dizer que o enunciado se coloca como uma condição de verdade não é o mesmo que restringir a visibilidade ao enunciado. Fazê-lo seria reduzir o pensamento foucaultiano a uma filosofia da linguagem, “o que segundo Deleuze é inadmissível” (MACHADO, 2010, p. 166). Para atestar a não redução do enunciado a meros elementos linguísticos, Foucault informa que (2009, p. 123):

\begin{abstract}
O enunciado não é uma unidade elementar que viria somar-se ou misturar-se às unidades descritas pela gramática ou pela lógica. Não pode ser isolado como uma frase, uma proposição ou um ato de formulação. Descrever um enunciado não significa isolar e caracterizar um segmento horizontal, mas definir as condições nas quais se realizou a função que deu a uma série de signos [...] uma existência, e uma existência específica.
\end{abstract}

Pelo fragmento de Arqueologia do saber (2009) fica evidente que enunciado é uma função que remete a uma lei de coexistência, que Foucault denomina como formação discursiva. É ela que estabelece a regularidade de determinados enunciados. Apesar dessa pretensa regularidade, a formação "se caracteriza não por princípios de construção, mas por uma dispersão de fato, já que ela é para os enunciados não uma condição de possibilidade, mas [como já dito] uma lei de coexistência, e os enunciados [...] em troca, são conjuntos caracterizados por sua modalidade de existência” (FOUCAULT, 2009, p. 132).

Parelho à noção de formação discursiva, está o conceito de discurso. Segundo Foucault (2009), o discurso pode ser entendido como um conjunto de enunciados apoiados a uma mesma formação discursiva. $O$ discurso não é uma simples unidade que surge na história, ele é, “de parte a parte, histórico - fragmento de história, unidade e descontinuidade na própria história" (FOUCAULT, 2009, p. 133).

Justamente por ser histórico de ponta a ponta, e pela história estar marcada por jogos de poder que podem ser encontrados nas sociedades ao longo do tempo, o discurso da forma como é concebido por Foucault (2008; 2009), não poderia simplesmente ignorar as possibilidades de interdições, de controle, de normatizações; não poderia, portanto, ignorar a existência de uma ordem adstrita ao discurso, que estabelece o que pode e o que não pode ser dito em determinadas situações. Como diz Foucault (2008, p. 37): 
[...] ninguém entrará na ordem do discurso se não satisfazer a certas exigências ou se não for, de início, qualificado para fazê-lo. Mais precisamente: nem todas as regiões do discurso são igualmente abertas e penetráveis; algumas são altamente proibidas (diferenciadas e diferenciantes) enquanto outras parecem quase abertas a todos os ventos e postas, sem restrição prévia, à disposição de um sujeito que fala.

O excerto, extraído da obra $A$ ordem do discurso (2008), mostra como a produção discursiva em nossa sociedade é organizada, selecionada e redistribuída por alguns procedimentos, como a exclusão, a sujeição e a rarefação. Ao suscitá-los, Foucault:

[...] delineia sua passagem para uma análise genealógica, por meio da qual, dedicarse-á a investigar como se formaram, através de, apesar de, ou com o apoio desses sistemas de coerção, séries de discursos; qual foi a norma específica de cada uma dessas séries e quais foram as suas condições de aparição, de crescimento, de variação. Para Foucault, a partir desse momento, as descrições críticas e genealógicas devem alternar-se, apoiar-se umas nas outras e se completarem. (GREGOLIN, 2004, p. 109)

Em outros termos, na abordagem genealógica presente nas obras de Foucault a partir dos anos de 1970, o autor não se contentava mais em avaliar ou precisar as "condições arqueológicas dos enunciados, mas começava a interrogar os sistemas de exclusão e rarefação que envolve toda a enunciação discursiva" (DUARTE, 2009, p. 46). A partir dessa mudança, a linguagem antes inscrita no aparecimento e transformação dos saberes, passa a ser pensada também a partir de elementos de natureza estratégica ou procedimentos de exclusão (Cf. FOUCAULT, 2008).

\section{Do uso à ordem discursiva: apontamentos sobre a linguagem em Foucault e Rorty}

Ao compreendermos que tanto no pensamento de Rorty, por sua influência wittgensteiniana, quanto de Foucault, seja possível pensar a existência de jogos de linguagem ${ }^{1}$ que são pactuados socialmente, de modo circunstancial e histórico, com determinados mecanismos de conservação, talvez a diferença mais evidente entre as posições rortyanas e foucaultianas acerca da linguagem esteja na maneira como os sujeitos pactuam dentro desses jogos.

\footnotetext{
1 “[Para Wittgenstein] um jogo de linguagem é composto por signos ligados às práticas de seus respectivos usos, as quais terminam por mostrar como os próprios signos estão servindo de critério para avaliar se a aplicação dessas regras simbólicas está sendo adequada ou não. Num jogo a mesma regra se aplica indefinidamente mas chega a resultados imprevisíveis, de sorte que o seu uso adequado implica a criação de um halo de diferenças" (GIANOTTI, 2006, p. 55).
} 
Em Rorty, a linguagem tem uma dimensão muito mais pragmática, prática do que em Foucault. Nesse sentido, o uso da linguagem:

[...] não depende da relação referencial entre língua e mundo. O que é afirmado ou pressuposto é dito em uma situação de emprego, em um contexto dialógico, como parte de culturas e formas de vida. Nessa dimensão pragmática dos jogos de linguagem, dos atos de fala com suas características operatórias, e no solo discursivo de produção da linguagem, além da competência de um falante pela qual há compreensão lingüística, há os componentes situacionais (ARAUJO, 2007, p. 92).

Apesar do Pragmatismo, em geral, não preterir os componentes situacionais, a utilização destes se limita a busca pela pertinência de determinados usos frente a outros, ou como o próprio Rorty (1994, p. 39) questiona: "devemos restringir-nos a perguntas como o uso [de determinadas] palavras atrapalha [o] uso [de outras]?”.

Foucault, por sua vez, não se limita a uma tarefa pragmática de simplesmente questionar sobre os usos dos enunciados. Conforme tratam Dreyfus e Rabinow (1995):

\begin{abstract}
Foucault não está interessado no modo pelo qual oradores sérios e ouvintes entendem-se mutuamente em ocasiões específicas. Não há dúvida de que Foucault concordaria com os escritores, de Wittgenstein passando por Kuhn e até Searle, de que o entendimento específico dos atos discursivos específicos envolvem uma partilha de práticas básicas já estabelecidas, uma vez que ninguém pode jamais afirmar, na sua totalidade, o que está querendo dizer, com a finalidade de excluir, a priori, qualquer possibilidade de mal-entendido. (DREYFUS \& RABINOW, 1995, p. 54).
\end{abstract}

O excerto acima mostra como apesar de existirem traços semelhantes entre Wittgenstein — por conseguinte Rorty — e Foucault, o objetivo deste último não é tecer uma investigação acerca dos usos de linguagem, mas questionar porque determinados usos se fazem pertinentes e outros não. A hipótese foucaultiana, que talvez sintetize a grande diferença entre os pensadores aqui abordados, está na ordem do discurso. É essa ordem que estabelece uma "polícia discursiva que devemos reativar em cada um dos nossos discursos" (FOUCAULT, 2008, p. 35). É ela que, de certa forma, justifica as opções do que pode ser dito, do que pode ser pensado, do que pode ser conhecido. Em outros termos, cada época, cada "formação histórica remete, como um a apriori, a um espaço das forças que é o lugar ou o não-lugar das mutações, da mudança, do devir" (MACHADO, 2010, p. 173). É justamente este o espaço que Rorty não buscou problematizar em suas análises. 


\section{CONCLUSÃO}

Ressalta-se a importância do tema analisado por perpassar eixos transdisciplinares do conhecimento, como: a História, a Filosofia e a Linguística. Suscitar a questão da linguagem em autores como Rorty e Foucault não implica somente uma descrição de correntes filosóficas do pensamento, mas significa suscitar conhecimentos constantes nas outras áreas citadas. Diante de tal justificativa, o objetivo do artigo foi retomar as discussões acerca da linguagem empreendidas pelo filósofo americano Richard Rorty na primeira parte de sua obra Contingência, ironia e solidariedade (1994), e relacioná-las ao pensamento de Michel Foucault, sobretudo por meio das obras Arqueologia do saber (2009) e A Ordem do Discurso (2008).

Antes de empreender tal relação foi preciso remontar brevemente o pensamento dos autores citados a fim de explicitar como os mesmos concebiam as noções de linguagem ou termos adjacentes à mesma como: enunciado, discurso, etc.

Por meio da breve exposição do pensamento desses autores, pôde-se notar que linguagem concebida por Rorty se assemelha à de Foucault ao se colocar como produtora, e não intérprete, das verdades. Em outros termos, em ambos a verdade não está dada, mas é pactuada, produzida. O que os difere mais nitidamente é o modus operandi pela qual a linguagem atua. Para explicitar isso melhor, é preciso lembrar que a linguagem proposta por Rorty se define a partir dos usos que os indivíduos fazem da mesma em uma dada contextura. Nesse sentido, não importa porque determinado uso se coloca e outro não, mas seu simples modo de utilização, sua prática frente às necessidades humana. Em outros termos, a linguagem proposta por Rorty atua em sua "pura contingência" (RORTY, 1994, p. 55). Por outro lado, a prática de linguagem, ou discursiva, tratada por Foucault não se confunde a uma mera operação expressiva, ela se refere a "um conjunto de regras anônimas, históricas [que definem] a condição de exercício da função enunciativa" (FOUCAULT, 2009, p. 133).

Assim, se em Rorty a linguagem está exposta a sua pura contingência, em Foucault, ela está alicerçada a uma condição de possibilidade histórica que determina o que pode ser dito em uma dada conjuntura. Muito embora o jogo de linguagem rortyano, de influência wittgensteiniana, também seja histórico, ele continua atrelado a um modo de atuação pragmático que, de certo modo, o impedem de considerar as ordens discursivas adstritas aos enunciados. Em suma, se para Foucault a história é um mecanismo preponderante para dizer por que as coisas são, a linguagem foucaultiana não poderia, por si só, obliterar essa condição 
de visibilidade histórica. E mesmo que esta história foucaultiana, de matriz nietzschiana, também seja contingente, ainda assim, ela continua sendo história, com suas diferenças e repetições.

\section{REFERÊNCIAS}

ARAUJO, I. L. Subjetividade e linguagem são mutuamente excludentes? Princípios, Natal, v. 14, n. 21, jan./jun. 2007, p. 83-103.

DREYFUS, H. L; RABINOW, P. Michel Foucault, uma trajetória filosófica: para além do estruturalismo e da hermenêutica. Trad.: Vera Porto Carrero. Rio de Janeiro: Forense Universitária, 1995.

DUARTE, André. Foucault no século XXI. Dossiê Foucault. Revista Cult. ano 12, n. 134, abr. 2009.

FOUCAULT, M. A ordem do discurso. Trad. Laura Fraga de Almeida Sampaio. 16. ed. São Paulo: Loyola, 2008.

FOUCAULT, M. Arqueologia do saber. Trad. Luiz Felipe Baeta Neves. 7.ed. Rio de Janeiro: Forense, 2009.

GIANOTTI, J.A. Dois jogos de pensar. Novos estudos. n. 75, jul. 2006. Disponível em: <http://www.scielo.br/pdf/nec/n75/a04n75.pdf>. (Acessado em: 01 ago. 2013).

GREGOLIN, Maria do Rosário. Foucault e Pechêux na construção da análise do discurso: diálogos e duelos. São Carlos: Claraluz, 2004.

MACHADO, R. As três dimensões do pensamento. Deleuze, a arte e a filosofia. 2.ed. Rio de Janeiro: Zahar, 2010.

MOHALLEM, J.C. O pragmatismo de Rorty. In: A redescrição pragmática do sujeito. Mente, Cérebro \& Filosofia. São Paulo: Duetto, 2008, p. 48-55. ISBN: 978-85-99535-47-9.

NARVAZ, M.G.; NARDI, H.C.; MORALES, B. Nas tramas do discurso: a abordagem discursiva de Michel Pêcheux e de michel Foucault. Revista de Psicologia Política. v. 6, n. 12. 2006. (Acessado em: 1 ago. 2013). Disponível em: <http://www.fafich.ufmg.br/rpp/seer/ojs/viewarticle.php?id=14\&layout=html>.

RORTY, R. Contingência, ironia e solidariedade. Lisboa: Presença, 1994. 